\title{
Introduction to Part 2
}

To paraphrase the late Binyavanga Wainaina: why do animals in Africa bear names, but people don't? Much indeed has been said and written about 'nature' in Africa (to paraphrase an - unfortunately anonymous - colleague: nature is where Bambi lives); the same is true for the (macro-)economic determinants of life on the continent. Obviously, these circumstances are beyond any individual's control (or even beyond the power of individual states); nevertheless, they are the consequence of decisions made in the past, and will have an enormous bearing on those of tomorrow.

The five contributions in this second section adopt a helicopter view on some of the ecological and economic challenges that confront Africa. In the first chapter, Ian Scoones turns his attention to what he refers to as convivial development, as an alternative to dominant approaches that depart from a crisis narrative and that invariably reach for solutions aimed at preserving the status quo, or securing an uncertain situation. He argues that Africa is, in many regards, ahead of the rest of the world and that a truly decolonial approach should be based on learning from.

Next is Michael Bollig's contribution. He asks the pertinent question for whom conservation efforts are intended as he explores the often contradictory approaches that have recently emerged. His starting point is that the current ecological crisis is also a social crisis.

Bollig's remark that ecology is intertwined with the global economy is further corroborated by Eric Kioko, who scrutinizes the mechanisms and impact of the illegal exploitation of Africa's flora - a less mediatized and often disregarded environmental crime that, in terms of revenue, leaves the illegal trade in wildlife far behind and fuels a network of loggers, smugglers, transporters and buyers that spans the globe.

In the fourth contribution Thomas Widlok and Ndapewa Fenny Nakanyete, too, take a stance against the prevailing assumption that Africa 'lags behind'. In many regards, including ecology management and policy, Africa is foreshadowing the future. Crucial to their argument is the importance they attach to time-framing and its impact on the process of decision-making.

Finally, Romie Nghitevelekwa discusses the dynamics of land commodification and contends that land reform is the most obvious way to reduce inequality and prevent further dispossession of, among others, communal lands. Focusing on Namibia, hers is the case of the 'new' scramble for the last African frontiers by foreign investors, and she raises important questions on the effects and sustainability of market penetration. 


\title{
A New Politics of Uncertainty: Towards Convivial Development in Africa
}

\author{
Ian Scoones
}

\section{Rethinking African Development}

Africa continues to face multiple uncertainties - climate chaos, food insecurity, migration flows, economic volatility, conflict, epidemic disease outbreaks, fragile governance and more. Indeed, it is these issues that dominate popular academic and media coverage of Africa. It's all doom and gloom, disaster and catastrophe. The solution, so the narrative goes, is economic and governance 'reform', aiming to 'stabilize' economies and societies and so control uncertainty. Such interventions are, in turn, combined with 'emergency' humanitarian interventions to deal with the worst. Aid and investment packages therefore aim to control, to manage uncertainties, to reinstate a stable status quo, while emergency responses override normal routines, imposing an often securitized solution, blotting out local initiative and agency (Yanguas 2018).

In this short essay, I ask if there are alternatives to this dominant approach to aid and development in Africa that foster what I call 'convivial development', one that fulsomely embraces uncertainty, ambiguity and even ignorance (Scoones 2019; Scoones and Stirling 2020; Stirling 2003). Following Ivan Illich (1973), I take convivial development to mean an approach that engages with context, facilitates inclusion of multiple knowledges and skills, fosters a caring approach to people and environments centred on social justice and, as a result, necessarily embraces complexity and uncertainty.

I make the case that, in many respects, Africa is ahead of the game in constructing such alternatives from the margins, and that the Global North, also confronting the multiple uncertainties of a turbulent world - most recently and dramatically the COVID-19 pandemic - should start learning from Africa, reversing the flow of development thinking and practice.

\section{Development as Control: The Failures of 'Progressive} Neoliberalism'

The dominant control-oriented narrative of development for Africa has resulted in numerous projects and programmes, most of which fail. Whether

(C) IAN SCOONES, 2022 | DOI:10.1163/9789004471641_009 
the disastrous structural adjustment reforms imposed by the World Bank and International Monetary Fund (IMF) in the 1980s and 1990s, or the more modulated 'good governance' interventions that followed, they were all premised on an assumption of control, and the creation of stable, liberal economies and democracies in the image of the West. While China offers a different model through its brave new Belt and Road Initiative, the story is the same, although the politics are different.

Yet, the assumptions are flawed and the dangerous fallacies of control are exposed, perhaps especially in African contexts. Simplistic technocratic impositions fall apart, and the ideal-type models of Western (or Chinese) development fail, even when ameliorative additions, such as 'participation', are bolted on. The colonization project of aid-led development, whether emanating from the North or South, despite the power, influence and resources, has been shown to be seriously lacking (Antunes de Oliveira 2019).

Even in the Global North, the old order, constructed around various forms of 'progressive neoliberalism' (Fraser 2017) and pushed through aid programmes to Africa, is being challenged. Climate change, for example, means that economic systems and a commitment to growth at all costs, have to be overhauled (Kallis and March 2015). The financial crash has meant that approaches to financialization have to be fundamentally re-thought (Ellis et al. 2014). The COVID-19 pandemic requires a radical rethinking of disease preparedness and response (Leach et al. 2020). And the rise of authoritarian populist movements, and the sustained attack on liberal values, is resulting in a refashioning of once democratic regimes and liberal economies (Scoones et al. 2018).

Facing up to uncertainty is at the heart of all these challenges. One response is to reinforce the technocratic order, find ever more elaborate technological and governance responses to keep control in the face of rising uncertainty. Whether geo-engineering or climate-smart cities to confront climate chaos, or tighter regulation of banks and finance houses to offset a future economic meltdown, such approaches all rely on a politics of control, which frequently resorts to securitized, sometimes even militarized, responses in the face of unfolding crises and emergencies (Adey et al. 2015).

The increasingly apocalyptic language of threat, breakdown and collapse fuels anxiety, fear and isolationism. It also creates space for regressive forces, which, in the absence of alternatives, feed off a sense of helplessness, offering order and control through increasing authoritarianism. A populist politics of blame emerges - accusing 'foreigners' and 'migrants' and attacking a remote 'elite' on behalf of 'the people'. Regressive, nationalist versions of authoritarian populism create a powerful imaginary of a past when uncertainty and fear did not impinge. And such narratives can have a religious inflection, one 
that deploys religious beliefs to generate certainties, whether evangelical Christianity, Hindu nationalism or fundamentalist Islam.

The failures of neoliberal styles of development are littered across Africa. The 'Africa rising' slogan was short-lived, as the fragilities and dependencies of economies and polities were exposed (Taylor 2016). The flood of investment that was to follow the post-crash 'land rush' never materialized, and the painful struggles against corporate violence continue across the region, whether around biofuel plantations in Ghana or geothermal plants and oil fields in Kenya (Hall et al. 2015; Lind et al. 2020). And, at the same time, the inroads made by extremism of all sorts are undermining whole regions, alongside the fabric of emerging democracies. Whether this is violent insurgency in the Sahel, Somalia or northern Mozambique or the attack on gay rights in Uganda, for example, the same attempts at control and creating an imagined, regulated order are seen.

Embracing Uncertainty: What are the Alternatives?

So what are the alternatives? How can embracing uncertainty generate emancipatory futures and alternative imaginaries of development in Africa? As the multiple failures of neoliberal capitalism are tormenting the West (at the same time as even China's seemingly endless growth path is faltering), can Africa lead the way in prefiguring a future where a different approach is realized, one that does not fall into the fallacy of control, but encourages a more adaptive, responsive, reflexive approach, redefining what we mean by development, progress and modernity?

While arguing against the idea that somehow eliminating uncertainty provides the magic bullet for development, I want to make the case that alternatives that genuinely embrace uncertainty are already happening, but they have been suppressed by standardized, regimented, control-oriented development approaches. Where can we find such alternative development approaches? Certainly, not in most of the aid agencies, NGO s, foundations, technical departments and government offices that have presided over failed development for the last half-century or so. In various ways, dressed up in diverse buzzwords, these have all become trapped in the expert-led, control paradigm of the past, which has fostered the failed neoliberal development project and ignored or supressed uncertainty.

But, alternatives can be found, usually on the margins, perhaps among the wreckage of a failed aid project or investment programme. Here, in highly dynamic, informal settings, improvisation, practised performance, 
experimentation and continuous reflexive adaptation are a necessity, often in parallel 'twilight' institutions (Lund 2007). For, this is what daily life is like, and has to be. Uncertainty is necessarily embedded in the everyday practices on the margins, of those living in precarity. It is therefore these vernacular understandings, rooted in long-standing collaborative practices and diverse knowledge and cultures, which fully embrace responses to uncertainty.

This is not a call to reify and recapture a static form of 'indigenous' knowledge and culture, as such settings are always changing, always uncertain (Agrawal 1995). Nor are simplistic versions of 'participation' the solution (Cooke and Kothari 2001). Local knowledges and cultures are deployed not for timeless rituals, but to cope with and respond to change. This generates innovation, sometimes social, sometimes technical, but always co-produced in context (Smith et al. 2014), not as some form of instrumental 'participatory development'. These are the places of 'real economies', created and practised through social investments, and rooted in place (de Alcantara 1992). These are also the sites where new forms of politics emerge, necessarily linked to collective action, mutual support and community solidarity; because, to respond to radical everyday uncertainties, people must work together (Bollier 2014; Nightingale 2019).

These flexible, informal, collective and rooted responses, I argue, cumulatively result in the remaking of the economy, the state and society from below through new forms of conviviality, and so require a radical rethinking of development.

Responding to Uncertainty, Reinventing Development: Three Examples

What might this entail? Three short examples show how, in response to the uncertainties of food insecurity, drought and infectious disease outbreaks, a more hopeful, flexible and convivial alternative is already being generated.

\subsection{Food Insecurity in Zimbabwe}

My first example focuses on how farmers innovate to confront the challenges of food insecurity in Zimbabwe. For sure, they make use of existing technologies - improved seeds, chemical fertilizers, irrigation equipment and so on but these have to be adjusted for use in their own settings. Standard, controloriented development suggests a package, designed remotely by experts, sometimes restricted cut 'in form' by proprietary technologies. But, in practice, this may be inappropriate: the soils are different, the labour is unavailable and 
the crop does not suit local tastes. What happens instead is the deployment of knowledges, practices and a mix of technologies and techniques as part of a farming 'performance', where new solutions to contextual problems are sought (Flachs and Richards 2018).

Research from Zimbabwe (and elsewhere) points to the potentials of local open-source seed breeding and sharing (Scoones 1996), the use of cheap, small pumps for garden irrigation (Scoones et al. 2019), practices of soil fertility management and soil and water conservation that suit the particular setting (Motsi et al. 2004; Scoones 2015) and so on. Uncertainties of climate, plant genetics, soil fertility response, as well as labour and social organization, have to be responded to as part of the unfolding performance. Improvisation, experimentation, adaptation and flexibility are the keywords.

This, of course, is what has always happened in African farming systems, but how can such approaches become central to research and extension systems, as well as technology and innovation projects, without falling into the trap of narrow, technocratic research and single package approaches? Responding to uncertainty requires extended menus, widened choice and an encouragement of diverse performances to create hybrid alternatives, a form of 'bricolage' (Cleaver 2012). The role of development actors - for example agricultural researchers and extension workers - is to extend the menu and learn from the performances, be part of a continuous loop of widely-shared collective learning (Scoones and Thompson 2009).

\subsection{Pastoralists' Responses to Drought in East Africa}

My second example highlights mobility as central to pastoralists' responses to uncertainty in dryland East Africa. Transhumant movements have for centuries ensured that grazing is found, even in the face of highly variable rainfall (Krätli and Schareika 2010; Scoones 1994). Major drought events may require specific innovations - finding out where grazing and water is, negotiating with neighbours, moving to new areas. New technologies, such as mobile phones, linked in turn to weather satellites via the Internet, can facilitate such movements, but the basic principles still apply. Mobility is vital to ensure a reliable system in the face of uncertainty (Roe 2020; Roe et al. 1998). Moving requires strong social institutions, linking across kin groups and clans, and allowing collective work - including, for example, scouting out areas, striking grazing contracts and managing herding labour (Turner and Schlecht 2019). Uncertainties are best not faced alone, and collectivities have to be formed, sometimes quite rapidly, to respond. Strong bonds, deep, shared understandings and functioning institutions are all essential components that assure mobility and successful resource management (Nori 2019; Schnegg 2018). 
Many have long predicted the end of mobile pastoralism, arguing for a more 'modern', settled, controlled approach, but sedentary living cannot cope with high variability, and so, even if classic transhumance is constrained, new forms of mobility are invented. In some cases, where rangelands have been enclosed and privatized, then pastoralists no longer move animals, but must move fodder and water, using the same principles (Catley et al. 2013). In our 'liquid times' (cf. Bauman 2013), mobile lives and livelihoods are central, yet a control-oriented stance often establishes borders and boundaries, controlling movement as something undesirable. The sedentary view advocates stability, order and fixity, but such features undermine responses to uncertainty (Scott 2017). Learning lessons from pastoralists about how movement is managed through diverse knowledges, practices and technologies - and the processes of innovation that underpin them may help overturn the sedentary view of development, and allow us all to embrace uncertainty, whether in respect of climate change, volatile markets or fragile institutional and political systems (Scoones 2019).

\subsection{Responding to Ebola in West Africa}

My third example focuses on outbreaks of infectious diseases. These can suddenly appear, and may cause huge mortalities if uncontrolled. The Ebola outbreaks in West Africa and the Democratic Republic of the Congo are examples. The conventional approach to infectious disease control is to trace the source, isolate infected people and areas and administer drugs and vaccines. It is usually a top-down response, led by medical professionals, sometimes reinforced by security personnel. The trouble is it does not always work.

In the case of Ebola in West Africa, for example, local responses to the disease - through controlling movements, changing burial practices and so on - were crucial in turning the situation around (Richards 2016; Wilkinson et al. 2017). Indeed, a medicalized, securitized response often makes matters worse, for the fear that the emergency response generates makes people reluctant to report cases, so they avoid treatment centres, even if desperately ill. Distrust, rumour and misinformation multiply. Instead, in Sierra Leone it was people's own 'cultural logics' - practical knowledge of how to deal with uncertainty - that were central, as were collective, village-level responses, driven by local institutions (Leach and Hewlett 2010).

Uncertainties affect different people in contrasting ways: class, gender, age, occupation, location all matter (Dzingirai et al. 2017). Only through working together and understanding social difference was Ebola confronted. It involved linking insights from different knowledge and belief systems; it meant taking embedded experience and emotion, not just technical data, seriously and it 
required developing collective, local institutional responses, not parachuted from outside but built from within. Through this hard-won experience, an alternative approach to infectious disease management can be envisaged. It is one that recognizes that the current approach, and many of the existing organizations and sources of expertise, is clearly not fit for purpose, as the world has learned so tragically during the COVID-19 pandemic. Instead, it is those living with disease and being challenged by uncertainties on a daily basis that must take the lead.

\section{5 \\ Confronting Uncertainty: Principles of Convivial Development}

Across these examples, a number of principles can be identified. Responding to uncertainties usually requires flexible, adaptive responses, not fixed, standardized packages. Experiences of uncertainty will differ depending on who or where you are, making situated perspectives and diverse knowledges essential. Differentiated actions always need to be responsive to social difference, cultural beliefs and lived experiences. Building the solidarities necessary for collective responses is vital, and this requires strong, rooted institutions, effective local leadership and the autonomy to create new solutions. Innovation, improvisation and creativity are key, and these emerge through flexible performances involving multiple actors, and no predefined script. Therefore, sharing, extending and multiplying such innovations as responses to uncertainty are centrally what development needs to be about, suggesting new roles for experts, state agencies and development projects.

This in turn means rejecting the 'we know best' stance of mainstream development, decolonizing the process and encouraging emergent, grounded, creative solutions. These principles, learnt from those at the margins - in these cases southern African farmers, mobile East African pastoralists and West African villagers confronting Ebola - make up, in the words of Ivan Illich (1973), the varied 'tools for conviviality'. Thus, convivial development - one that is responsible, social, shared and led by a political community, not experts or managers - is an approach that truly embraces uncertainty - outside the mainstream, in the margins and already being practised across Africa.

This positive vision eschews the hype of 'Africa rising', but focuses on the real solutions being generated for the current, universal dilemmas of development, North and South. Rather than repeating the failures of technocratic development, perhaps we all should turn our gaze elsewhere, and seek out the principles of convivial development on the ground, ones that genuinely embrace uncertainty, and generate a refashioned version of modernity and progress for Africa and the world. 


\section{Acknowledgements}

This chapter was written as part of the PASTRES (Pastoralism, Resilience, Uncertainty) programme (www.pastres.org), supported by a European Research Council Advanced Grant. Ideas here have also been developed over many years as part of the ESRC STEPS Centre's work on uncertainty (https:// steps-centre.org/uncertainty/).

\section{References}

Adey, P., B. Anderson and S. Graham. 2015. "Introduction: Governing emergencies: Beyond exceptionality." Theory, Culture and Society, 32, 2:3-17.

Agrawal, A. 1995. "Dismantling the divide between indigenous and scientific knowledge." Development and Change, 26, 3: 413-439.

Antunes de Oliveira, F. 2019. "Development for whom? Beyond the developed/underdeveloped dichotomy." Journal of International Relations and Development, 23: 924-946.

Bauman, Z. 2013. Liquid modernity. Chichester: John Wiley \& Sons.

Bollier, D. 2014. Think like a commoner. A short introduction to the life of the commons. Gabriola: New Society Publishers.

Catley, A., J. Lind and I. Scoones (Eds). 2013. Pastoralism and development in Africa. Dynamic change at the margins. London: Routledge.

Cleaver, F. 2012. Development through bricolage? Institutions and natural resource management. London: Earthscan.

Cooke, B. and U. Kothari (Eds). 2001. Participation: The new tyranny? London: Zed Books.

de Alcantara, C. H. (Ed.). 1992. Real markets: Social and political issues of food policy reform. London, Routledge.

Dzingirai, V., B. Bett, S. Bukachi, E. Lawson, L. Mangwanya, I. Scoones, L. Waldman, A. Wilkinson, M. Leach, and T. Winnebah. 2017. "Zoonotic diseases: Who gets sick, and why? Explorations from Africa." Critical Public Health, 27, 1: 97-110.

Ellis, L., A. Haldane and F. Moshirian. 2014. "Systemic risk, governance and global financial stability." Journal of Banking and Finance, 45: 175-181.

Flachs, A. and P. Richards. 2018. "Playing development roles: The political ecology of performance in agricultural development." Journal of Political Ecology, 25, 1: 638-646.

Fraser, N. 2017. "The end of progressive neoliberalism." Dissent, 2 January. www.dissentmagazine.org.

Hall, R., I. Scoones and D. Tsikata (Eds). 2015. Africa's land rush: Rural livelihoods and agrarian change. Woodbridge: James Currey.

Illich, I. 1973. Tools for conviviality. New York: Harper \& Row. 
Kallis, G. and H. March. 2015. "Imaginaries of hope: The utopianism of degrowth." Annals of the Association of American Geographers, 105: 36o-368.

Krätli, S. and N. Schareika. 2010. "Living off uncertainty: The intelligent animal production of dryland pastoralists." The European Journal of Development Research, 22: $605^{-622 .}$

Leach, M. and B. S. Hewlett. 2010. "Haemorrhagic fevers: Narratives, politics and pathways." In Epidemics, edited by S. Dry and M. Leach, 57-83. London: Routledge.

Leach, M., H. MacGregor, S. Ripoll, I. Scoones and A. Wilkinson. 2020. "Rethinking disease preparedness: Uncertainty and the politics of knowledge." Critical Public Health, DoI: 10.1080/09581596.2021.1885628.

Lind, J., D. Okenwa and I. Scoones (Eds). 2020. Land, investment and politics: Reconfiguring East Africa's pastoral drylands. Woodbridge: James Currey.

Lund, C. 2007. Twilight institutions: Public authority and local politics in Africa. Oxford: Blackwell.

Motsi, K. E., E. Chuma and B. B. Mukamuri. 2004. "Rainwater harvesting for sustainable agriculture in communal lands of Zimbabwe." Physics and Chemistry of the Earth, Parts $A / B / C$, 29, 15: 1069-1073.

Nightingale, A. J. 2019. "Commoning for inclusion? Political communities, commons, exclusion, property and socio-natural becomings." International Journal of the Commons, 13, 1: 16-35.

Nori, M. 2019. "Herding through uncertainties - regional perspectives. Exploring the interfaces of pastoralists and uncertainty." Robert Schuman Centre for Advanced Studies Research paper 68. DoI: 10.2139/ssrn.3457235.

Richards, P. 2016. Ebola: How a people's science helped end an epidemic. London: Zed Books.

Roe, E. 2020. A new policy narrative for pastoralism? Pastoralists as reliability professionals and pastoralist systems as infrastructure. STEPS working paper 113. Brighton: steps Centre.

Roe, E., L. Huntsinger and K. Labnow. 1998. "High reliability pastoralism." Journal of Arid Environments, 39, 1: 39-55.

Schnegg, M. 2018. "Institutional multiplexity: Social networks and community-based natural resource management." Sustainability Science, 13, 4: 1017-1030.

Scoones, I. (Ed.). 1994. Living with uncertainty: New directions in pastoral development in Africa. Rugby: Intermediate Technology Publications.

Scoones, I. 1996. Hazards and opportunities: Farming livelihoods in dryland Africa. Lessons from Zimbabwe. London: Zed Books.

Scoones, I. 2015. "Transforming soils: Transdisciplinary perspectives and pathways to sustainability." Current Opinion in Environmental Sustainability, 15: 20-24.

Scoones, I. 2019. What is uncertainty and why does it matter? ST EPS working paper, 105. Brighton: STEPS Centre. 
Scoones, I. and A. Stirling (Eds). 2020. The politics of uncertainty: Challenges of transformation. London: Routledge.

Scoones, I. and J. Thompson. 2009. Farmer first revisited: Innovation for agricultural research and development. Rugby: Practical Action Publishing.

Scoones, I., M. Edelman, S. M. Borras Jr, R. Hall, W. Wolford and B. White. 2018. "Emancipatory rural politics: Confronting authoritarian populism." The Journal of Peasant Studies, 45, 1: 1-20.

Scoones, I., F. Murimbarimba and J. Mahenehene. 2019. "Irrigating Zimbabwe after land reform: The potential of farmer-led systems." Water Alternatives, 12, 1: 88-106.

Scott, J. C. 2017. Against the grain: A deep history of the earliest states. New Haven: Yale University Press.

Smith, A., M. Fressoli and H. Thomas. 2014. "Grassroots innovation movements: Challenges and contributions." Journal of Cleaner Production, 63: 114-124.

Stirling, A. 2003. "Risk, uncertainty and precaution: Some instrumental implications from the social sciences." In Negotiating environmental change, edited by F. Berkhout, M. Leach and I. Scoones, 33-76. Cheltenham: Edward Elgar.

Taylor, I. 2016. "Dependency redux: Why Africa is not rising." Review of African Political Economy, 43, 147: 8-25.

Turner, M. D. and E. Schlecht. 2019. "Livestock mobility in sub-Saharan Africa: A critical review." Pastoralism, 9, 13. DOI: 10.1186/s13570-019-015o-z.

Wilkinson, A., M. Parker, F. Martineau and M. Leach. 2017. "Engaging 'communities': Anthropological insights from the West African Ebola epidemic." Philosophical Transactions of the Royal Society B, 372, 1721. DOI: 10.1098/rstb.2016.0305.

Yanguas, P. 2018. Why we lie about aid: Development and the messy politics of change. London: Zed Books. 